\title{
ABERTURA DE DIREITOS AUTORAIS NA INTERNET PARA SATISFAÇÃO DE DIREITOS DE LIVRE EXPRESSÃO E PARTICIPAÇÃO CULTURAL
}

\section{OPEN COPYRIGHTS ON INTERNET IN ORDER TO SATISFY FREE SPEECH AND CULTURAL PARTICIPATION RIGHTS}

\author{
Alexandre Henrique Tavares Saldanha ${ }^{1}$
}

\begin{abstract}
RESUMO:
Este trabalho procura colaborar com o debate que envolve a relação entre direitos autorais e liberdade de expressão, propondo uma releitura destas normas jurídicas, no sentido de sua maior abertura, para que possa ser possível satisfazer direitos humanos de acesso á cultura, no contexto da cibercultura. A hipótese de problema está na relação paradoxal criada entre a propensão ao fechamento provocada pelos direitos autorais, contra a exigência de acesso aberto à participação cultural surgida como direito fundamental no contexto da sociedade da informação. O objetivo é justamente demonstrar esta tensa relação e propor um modelo de direitos de autor mais adequado às características sociais do século XXI, para que possam ser satisfeitos os direitos de acesso e participação na cultura. O desenvolvimento do trabalho é baseado em revisão de literatura demonstrativa do debate proposto.
\end{abstract}

Palavras-chave: Direitos Autorais; Liberdade de Expressão; Internet

\begin{abstract}
:
This work aims to contribute on the debate involving copyrights and freedom of expression, proposing these legal norms rereading, making it more open for various uses, in order to make possible to satisfy human rights of culture access in cyberculture social context. The hypothesis worked on this paper lies in the paradoxical relationship created between copyrights propensity for closure and control against requirements for open access and free cultural participation understood as effectual fundamental rights in information society. The research objective is precisely demonstrating this tense relationship and proposing a copyrights model more adequate to 21 st century social characteristics. The work was developed based on literature review in order to demonstrate the proposed debate and reinforce the showed arguments.
\end{abstract}

Keywords: Copyrights; Freedom of Speech; Internet.

\footnotetext{
1 Doutor em Direito pela UFPE. Professor na Universidade Católica de Pernambuco. Membro da Comissão de Propriedade Intelectual da OAB/PE Email: alexandresaldanha@hotmail.com
} 


\section{Introdução}

Este trabalho é consequência de pesquisa realizada sobre as interseções entre os temas da liberdade de expressão, dos direitos autorais e a concretização de direitos fundamentais relacionados ao gozo de bens culturais. As recentes transformações nas tecnologias da informação provocaram, e permanecem provocando, incontáveis impactos em comportamentos humanos, seja na dinâmica da economia, na interpretação das normas jurídicas e em praticamente quaisquer aspectos envolvendo relações intersubjetivas ou relações entre pessoas e meio ambiente. São de diferentes naturezas as consequências das transformações tecnológicas na forma como alguns direitos são interpretados e aplicados, isto porque com novos paradigmas científicos e culturais os direitos alteram sua forma de se manifestar. Além disto, surgem novos direitos ou novas dimensões de direitos, principalmente em manifestações jurídicas com multiplicidade de interpretações, a exemplo da categoria dos direitos humanos.

Diante disto, esta pesquisa parte de uma primeira hipótese, a de existir um novo paradigma cultural que se caracteriza por transformações decorrentes das inovações nas tecnologias da informação. Paradigma este que será referenciado no trabalho sob a designação "cibercultura", expressão que faz referência a um relacionamento hiperdimensionado entre homem e tecnologias digitais, se caracterizando por novos hábitos e novas exigências sociais. Daí produzir tantos impactos no sistema jurídico, pois com novas exigências sociais surgem novos direitos, ou reivindicam-se novos direitos. O que reflete numa outra hipótese levantada por este trabalho, a de que com a cibercultura a compreensão das liberdades comunicacionais (ou liberdades de expressão) recebem outros contornos. Com o amadurecimento da rede mundial de computadores, e das tecnologias a ela afins, a produção e o acesso à informação adquirem uma nova compreensão em decorrência das facilidades surgidas para oferecer e adquirir informações, para comunicar e ser comunicado. 
Com estas hipóteses apresentadas, é possível então arguir que os direitos fundamentais que envolvem acesso à cultura são, na contemporaneidade digital e informatizada, nunca foram tão facilmente alcançáveis, já que o fluxo de informações e as liberdades ciberculturais potencializam a satisfação destes direitos culturais. Porém, apesar das transformações e inovações no próprio sistema jurídico, alguns problemas sobre acesso à cultura permanecem os mesmos, a exemplo da infraestrutura normativa para a regulamentação dos direitos autorais, aqui compreendidos como normas que regulamentam não somente a relação entre criador e criação, mas também como normas que regulamentam o acesso e os usos dos bens culturais. Tais direitos de autor representam uma espécie de problema, do ponto de vista teórico, pois suas regras permanecem basicamente as mesmas de quando 0 acesso aos bens culturais só ocorreria por plataformas físicas.

Daí então o presente trabalho discutir a proposta de promover maior abertura dos direitos autorais, no intuito de satisfazer diretrizes estabelecidas pela compreensão da liberdade de expressão em ambiente digital para assim também satisfazer exigências sociais e normativas de acesso à cultura. A ideia a ser debatida é a de que o modelo tradicional de direitos autorais não é adequado para novos comportamentos típicos da cibercultura, principalmente aqueles que estão associados a liberdades fundamentais.

O objetivo não é defender extinção de direitos autorais, seja total ou parcialmente, mas sim uma adaptação de suas normas jurídicas a um contexto cultural onde há novas exigências sociais e, consequentemente, novos direitos considerados fundamentais ao exercício da personalidade, isto levando em consideração o fato de já existirem exemplos de iniciativas de criar regras autorais mais adaptáveis às características do século XXI.

O trabalho se desenvolverá a partir de revisão bibliográfica envolvendo os temas abordados na discussão, sem a pretensão de trazer dados objetivos ou quantitativos, mas sim de trazer argumentos que fundamentem uma releitura da relevância dos direitos autorais e sua relação com direitos fundamentais de liberdade. 


\title{
2 INTERNET E OPORTUNIDADES PARA AS LIBERDADES DE EXPRESSÃO
}

Seria cientificamente impossível, ou inadequado, conceituar objetivamente uma expressão tão complexa como liberdade, mas, para fins de promover debates e usar premissas válidas, é interessante ressaltar a natureza ambígua desta expressão, levando em consideração sua dimensão jurídica. Isto porque a compreensão jurídica de liberdade envolve esquema complexo de direitos e deveres, de obrigações de fazer e de não-fazer, criando assim um esquema não só composto por liberdades, mas também de "não-liberdades".

No âmbito desta discussão, a expressão liberdade pode ser usada para significar a valoração dada a ações, políticas, culturas ou instituições, considerando-as de importância fundamental, ainda que seja um ato de obediência ao direito positivo, ou a satisfação de interesses econômicos (BOBBIO, 1986, p. 708).

Por mais multidimensional que possa ser a compreensão da liberdade em seu aspecto jurídico, ela de forma genérica reflete um relacionamento entre condutas e tratamentos legais, uma interação entre pessoas e entre pessoas e instituições. Reflete um esquema que envolve condutas permitidas (liberdades) e não permitidas (proibições ou não-liberdades) e é justamente este esquema que vai interferir na identificação de determinado setor da sociedade, ou dos comportamentos sociais, como sendo livre, bem como na relação existente entre liberdade e estado democrático.

\begin{abstract}
Muitos crêem ser a democracia "uma sociedade livre". Todavia, as sociedades organizadas de estruturam mediante uma complexa rede de relações particulares de liberdade e não-liberdade (nada existe parecido com a liberdade em geral. Os cidadãos de uma democracia podem ter a liberdade política de participar do processo político mediante eleições livres. Os eleitores, os partidos e os grupos de pressão têm, portanto, o poder de limitar a liberdade dos candidatos que elegeram. A democracia exige que as "liberdades civis" sejam protegidas por direitos legalmente definidos e por deveres a eles correspondentes, que acabam implicando limitações da liberdade (BOBBIO, 1986, p. 710).
\end{abstract}

Se por um lado as liberdades estão previstas tanto na condição de direitos fundamentais previstos em constituições federais, quanto nas declarações 
internacionais de direitos humanos, elas se limitam entre si e são limitadas por outros direitos ou outros valores também eleitos como essenciais ao desenvolvimento humano. Daí o fato da liberdade de comunicação encontrar limite no direito à privacidade, daí a autolimitação entre direito de propriedade e liberdade de ir e vir, dentre outras relações que precisam ser balanceadas para não haver exageros na ênfase de uma em detrimento da denegação de outra liberdade fundamental. É nessa "equação" que se encontram as dimensões da liberdade, justamente nesse balanço que serão encontradas as reais possibilidades de tutela jurídica dos comportamentos livres.

Considerando características da complexa sociedade contemporânea, é possível analisar as questões que envolvem liberdades tanto sob perspectiva otimista quanto sob viés pessimista, até porque sua multiplicidade de interpretações não permitira apenas opiniões e diagnósticos unânimes. É possível falar em declínio das liberdades fundamentais diante de ameaças surgidas por processos de centralização de poder (como nas limitações à cidadania ocorridas na China, ou no crescimento de grupos políticos de extrema direita), pelo crescimento de oligopólios criados por grupos de interesses (oligopólios criados pelas empresas de comunicação, da indústria do entretenimento, e instituições financeiras, por exemplo), e por outras questões que tornam nebuloso o cenário das liberdades fundamentais ao humano (como crescimento da violência, corrida bélica e crescimento industrial ilimitado).

Em perspectiva oposta, a de evolução otimista das liberdades, elas vêm sendo cada vez mais afirmadas e repetidas tanto em documentos jurídico de eficácia nacional quanto nos de alcance internacional, e estes últimos não se resumem às declarações universais (RIVERO, 2006, p. 5). Além disto, há uma crescente reivindicação popular de espaços de participação livre, uma maior demanda por liberdades em setores diversos variando desde deliberações legislativas até formação de histórias da cultura pop, da possibilidade de livremente se comunicar, e ser comunicado, à poder questionar atos de gestão pública. Dentre os inúmeros problemas (paradigmas, controvérsias etc.) envolvendo as liberdades fundamentais, há aqueles que se relacionam mais intensamente com os impactos da cibercultura em comportamentos 
humanos e em dinâmicas sociais, requerendo enfrentamentos específicos para melhor tutela jurídica.

Em outros termos, existem liberdades que, em decorrência de novos paradigmas culturais surgidos com as transformações nas tecnologias da informação, irão exigir na contemporaneidade um tratamento jurídico ainda mais complexo do que outrora por estarem intrinsecamente envolvidas com características de uma cultura padrão surgida com a internet e com hábitos relativos a ela. Dentro do esquema anteriormente mencionado da relação entre liberdades e não-liberdades, é necessário analisar quais são os comportamentos de comunicação e expressão atualmente permitidos e quais não o são. Incluindo na análise a questão de identificar se as não-permissões são compatíveis com as exigências sociais de tempos de sociedade de informação.

A chamada liberdade de expressão não é a única liberdade associada à livre manifestação do pensamento. O desenvolvimento histórico dos comportamentos sociais e das revoluções tecnológicas fez serem identificadas outras formas de livre expressão do pensamento, daí hoje falar-se em liberdade de expressão artística, liberdade de comunicação e liberdade de informação, além de outras liberdades que, a depender do contexto hermenêutico-argumentativo, poderão ser mencionadas e reivindicadas. Falar especificamente em liberdade de expressão representa o direito que todos têm de livremente manifestar suas ideias, pensamentos, posições religiosas, ideológicas etc., o que é diferente da liberdade de comunicação, pois esta concede o direito de comunicar e ser comunicado, além de divulgar e receber informações. A liberdade de informação então é uma decorrência da liberdade de comunicação, porém com ênfase aos direitos fundamentais de informar algo, de se informar e de ser informado (FARIAS, 2007, p. 172).

A declaração universal dos direitos humanos, em seu artigo 19, prevê a liberdade de receber informações por quaisquer meios e sem limitações. Então, seria indiscutível debater sobre sua existência independente de outras liberdades. Questão mais complexa, e ao mesmo tempo relevante, está em associar o exercício de cidadania em geral, com o direito de todos serem informados sobre o que está acontecendo na sociedade, sobre fatos relevantes e, principalmente sobre conteúdos 
que transcendam as esferas do público e do privado, e atinja o nível de interesse geral (FARIAS, 2007, p. 175).

Uma vez informados, os cidadãos terão condições de melhor participar da sociedade civil, de melhor interagir com o poder público e, de certa forma, melhor compreender as próprias características culturais de sua sociedade, além de poder participar ativamente da criação de seu próprio contexto cultural. Participação ativa que se torna cada vez mais possível, por causa do contexto atual de ampla difusão e compartilhamentos de informação, mas, em paralelo, pode não interessar a quem detiver poderes de forma centralizada, podendo então ser tolhida por uso de instrumentos diversos, inclusive legais.

Assim como qualquer modalidade de liberdade, a que envolve informação é passível de diversos atos de tolhimentos, sejam praticados por poder público ou pelas próprias inter-relações entre particulares. Possivelmente com maior grau, as liberdades de expressão e informação se envolvem com interesses econômicos, seja por causa do valor da informação em sim (que na cibercultura passa a ser cada vez mais valiosa), ou por causa dos direitos e valores que estão em conexão com formas de expressão, como direitos autorais e o capital obtido pela economia do entretenimento. Daí, ser necessário buscar atingir um possível equilíbrio entre essas liberdades de comunicação e informação e os interesses econômicos com elas relacionados envolvidos, sem supravalorizar uma coisa em detrimento de outra (valorizando o acesso à cultura ainda que eliminando questões de direitos autorais, por exemplo, ou limitando acessos à informação para manter monopólios econômicos).

Qualquer hipótese representaria um desequilíbrio numa equação envolvendo valores de igual importância ao desenvolvimento pessoal, mas "se deixamos de lado o dogma da igualdade jurídica das vontades privadas e nos voltamos às realidades, a frequência das situações de dependência que permitem a quem se encontra em posição de superioridade impor sua vontade ao inferior fica evidente" (RIVERO, 2006, p. 205). Em outros termos, valorizar a igualdade proposta pela norma jurídica ignorando as evidentes diferenças socioeconômicas que são encontradas na relação 
economia versus acesso à cultura pode colaborar com a manutenção das forças como já estão, sem se preocupar com possíveis melhoras.

Considerando a hipótese de ser da própria natureza das liberdades jurídicas conter contradições, sedimentar dogmas, e se submeter a interesses tanto do poder público quanto de detentores de poder em setores privados, tudo isto no contexto da sociedade da informação potencializa os problemas que envolvem as liberdades de expressão. Isto porque se o ambiente digital cria diversos mecanismos para se expressar e para exercer as liberdades de informação, diversas também são as barreiras legais e econômicas que, de forma explícita ou implícita, tolhem o exercício destas liberdades fundamentais.

A expressão cibercultura representa algo além de formas de conexão entre comportamento humano e novas tecnologias, pois envolve aspirações pela construção de novos laços sociais, não fundados em circunstâncias territoriais, ou em instituições e poderes, mas baseados em novos interesses coletivos de compartilhamento, cooperação e processos abertos de informação e colaboração (LÉVY, 1999, p. 132). Não são as novas tecnologias com suas respectivas máquinas que criam a cibercultura, mas sim os usos humanos dessas e consequentes comportamentos que assim o fazem. O que o desenvolvimento tecnológico permite é o surgimento de novas exigências sociais, novas formas de interação entre particulares e entre particulares com poderes públicos.

Com a rede mundial de computadores interligando pessoas a tudo cria-se um mecanismo hábil a permitir o surgimento de uma nova concepção de inteligência coletiva e uma nova relação com a produção de conhecimentos. Atitudes como colaborar, compartilhar, cooperar ganham força com os mecanismos digitais disponíveis, em detrimento de lógicas privadas e individualistas como a sensação de ter, possuir, disponibilizar etc. Do ponto de vista ideal, se reconhece que o que melhor o ciberespaço proporciona é a possibilidade de reunir conhecimentos, criações, ideias de pessoas em diferentes locais e culturas, porém, esse acesso coletivo ao conhecimento representa mais uma fonte de novos problemas do que especificamente de soluções (LÉVY, 1999, p. 133). 
Se, por um lado, por meio da internet qualquer pessoa, usando das ferramentas capazes, pode transmitir informações e se expressar com liberdade e pode interagir com demais participantes da coletividade em ambiente digital, por outro lado este ambiente que potencializa manifestações e expressões passa a ser objeto de desejo de governos e grandes corporações, seja por questões geopolíticas ou por questões econômicas. Seja para dar abertura e liberdades, seja para tolher manifestações que não interessem, ou até que incomodem.

Os instrumentos oferecidos pela internet permitem que alguém demonstre uma expressão artística qualquer, sem que para isto precise de intermediários que facilitem o caminho entre obra e público. Basta alguém criar um blog, ou usar de seu perfil em rede social, para divulgar sua linha de confecções, seus utensílios, suas músicas e quaisquer obras de arte que realizou. Pessoas podem usar também das plataformas virtuais para expressar ideias e opiniões, ainda que não seja considerado alguém que represente uma empresa de comunicação.

Daí, uma das questões a serem enfrentadas seria a que envolve limites a essas liberdades potencializadas pela cibercultura, ou, até mesmo se não há uma falsa sensação de que essas liberdades estejam tão amplas assim. Da mesma forma que a rede é vista como uma plataforma para expressar, para satisfazer exigências de informação e para exercer liberdades, ela também cria um novo objeto a ser explorado comercialmente por novas formas de fazer negócios e novos desafios ao desenvolvimento de economias. Na sociedade da informação, a exploração econômica se baseia também em comercializar bens imateriais, como propriedade intelectual, e aqueles que representam os interesses econômicos privados vêem na rede um excelente ambiente para fazer negócios, e sendo assim, as liberdades trazidas pela cibercultura podem sofrer grandes supressões por políticas de censura e por normas legais de controle da propriedade intelectual, por exemplo (KRETSCHMANN, 2011, p. 77).

Situações surgidas com a cibercultura que terminaram envolvendo demandas judiciais e polêmicas exemplificam como a internet pode alterar a forma como os poderes se manifestam e a forma como o sistema jurídico está relacionando com 
manutenção ou abertura de oportunidades e controles. Casos como os grandes processos que envolvem de um lado grupos que disponibilizam gratuitamente conteúdo artístico-cultural (Napster, Soulseek, Piratebay etc.) e de outro, representantes de grandes corporações (Gravadoras, Editoras, Produtoras etc.), bem como os casos que envolvem punições políticas àqueles responsáveis pela divulgação não autorizada de informações de utilidade pública (Wikileaks e Julian Assange, ou Edward Snowden, dentre outros) servem para mostrar que é inadequado atribuir à internet propriamente dita qualquer conteúdo teleológico, qualquer promessa de valores, pois em rede tudo fica aparentemente relativo, o que a deixa mais complexa enquanto fenômeno social por causa dos paradoxos por ela provocados.

Ao mesmo tempo que a rede mundial de computadores oferece liberdades e satisfaz promessas de inclusão democrática, ela pode servir também para criar uma falsa sensação de liberdade, uma vez que é possível haver manipulações quanto ao que é disponibilizado na rede, controlando dados, informações ou qualquer conteúdo a ser acessado (KRETSCHMANN, 2011, p. 77).

Um dos paradoxos potencializado pela internet é o exemplo que envolve liberdade de expressão artística e regras tradicionais de direitos da propriedade intelectual. A relação entre acesso à cultura e manutenção da propriedade intelectual já é conflituosa muita antes da rede mundial de computadores e da cibercultura, mas, por causa das transformações tecnológicas e das características culturais surgidas neste contexto de transformação, esta dicotomia ganha aspectos incalculavelmente mais complexos.

Os instrumentos que surgem com o desenvolvimento das tecnologias da informação permitem que cada indivíduo manifeste em rede global seu potencial criativo, criando conteúdos que possivelmente não seriam criados, ou não seriam divulgados, em decorrência de incapacidades técnicas (ausência de recursos, espaços, repressão de mercado etc.). Mas, ainda que esta "catarse criativa" seja possível no contexto da cibercultura, todas estas manifestações culturais se submeterão às normas jurídicas tradicionais que tutelam a propriedade intelectual. Regras estas que podem não estar compatíveis com anseios surgidos com os padrões da cibercultura, tais como 
compartilhamento, interatividade, colaboração e divulgação gratuita, e assim, ao invés das normas jurídicas colaborarem com a satisfação de direitos culturais, terminarão tolhendo a liberdade fundamental de participar da criação de seu ambiente cultural. Ponto que são melhor trabalhados a seguir.

\section{DIREITOS AUTORAIS E LIMITES AO EXERCÍCIO DE DIREITOS CULTURAIS}

Os direitos autorais surgem como disciplina cujo objeto de tutela jurídica são as criações e as manifestações do intelecto criativo, caracterizando aquilo que passou a ser chamado de propriedade intelectual. Ramo do Direito bastante complexo, rico de contradições e repleto de problemas contemporâneos a serem enfrentados, principalmente por causa dos comportamentos associados à mencionada cibercultura, os direitos autorais já começam a apresentar sua complexidade a partir da própria designação. Há quem prefira usar a expressão propriedade intelectual como microssistema ao qual os direitos autorais estão ligados, e aqueles que vêem diferenças entre as expressões, preferindo não necessariamente vinculá-las.

Seja por uma idéia ou por outra (usando ou não usando a expressão "propriedade"), é interessante frisar que a proteção oferecida pelos direitos autorais alcança não somente o aspecto patrimonial do produto cultural, respondendo questões sobre quem dispõe da obra, pra qual uso, se pode copiar e compartilhar etc., como também alcança aspectos da relação entre criador e obra mais ligados aos direitos da personalidade, como ser apresentado ou identificado como autor.

Apesar do objeto dos direitos autorais alcançar também direitos da personalidade do autor, sua origem e desenvolvimento possuem natureza bastante patrimonialística. A partir do século XVII o intelectual, bem como o artista, trabalha de forma autônoma, independente de patrões da nobreza ou do clero, fazendo com que sua luta pela sobrevivência represente uma concorrência intelectual, uma competição entre criações e criadores (FRAGOSO, 2012, p. 130). O problema não está na inserção das lógicas capitais e patrimonial na proteção ao conteúdo autoral, mas sim reside no de identificar a quem isto realmente beneficia, se ao autor propriamente dito ou se ao 
intermediário, aquele cria o elo entre criador e público. Há registros históricos demonstrando que desde o início da comercialização dos livros, existiam prejuízos ao escritor porque os negócios envolvendo livros traziam vantagens aos editores, recebendo incentivos reais diferentes e mais vantajosos do que a remuneração dada aos escritores (FRAGOSO, 2012, p. 135).

Como o desenvolvimento histórico dos direitos autorais não é objeto de estudo deste trabalho, abstém-se então de uma maior pormenorização do percurso, frisando que o objetivo de ter traçado esta linha de raciocínio é o de frisar que, de forma geral, os direitos de autor se desenvolveram dando maior ênfase e relevância às questões patrimoniais a eles relacionadas. E assim, continuam a fazer. Melhor questão a ser analisada é a que questiona se os direitos autorais estão atingindo seus objetivos de proteger os criadores e incentivar a criatividade, ou se representam uma espécie de barreira legal para o surgimento de novas obras e novos exercícios do direito à criatividade, isto considerando o contexto tecnológico e cultural da sociedade da informação.

De início cabe ressaltar que é impossível deixar de associar os direitos autorais tanto à atividade de criar quanto à exploração econômica do que foi criado. A tutela da criação é o que justifica a própria existência do Direito de autor, uma vez que, não sendo identificada qualquer carga de contribuição criativa na obra, ela não merecerá a tutela deste direito, ficando o autor sem garantias jurídicas da compensação por esta contribuição dada à sociedade (ASCENSÃO, 1997, p. 3). O paradoxo está justamente sobre esta "compensação", pois originalmente ela surge por meio de garantias de exclusividade de usos, por meio de instrumentos que impedem a abundância do produto e que oferecem acesso a estes produtos artístico-culturais mediante pagamento hábil.

Em tese a sociedade aceita a contribuição dada pelo criador garantindo-lhe uma compensação pecuniária, que para ocorrer deverá provocar justificados impactos negativos na fluidez do acesso à cultura (ASCENSÃO, 1997, p. 4). Ou seja, faz parte da concepção original de direitos autorais a sua capacidade de tolher liberdades fundamentais (acesso à informação, acesso à cultura, liberdade de expressão etc.), em 
nome da satisfação financeira do responsável pela obra, ainda que este responsável não seja o próprio criador.

É possível argumentar que existe um direito fundamental de criar, de participar da criação de um patrimônio cultural, de livremente manifestar seu espírito criativo. Esta liberdade de criação "compreende o direito do indivíduo de gerar expressões intelectuais, sejam elas de caráter cultural (obras literárias ou artísticas), sejam elas de conteúdo científico ou técnico, sem qualquer restrição imotivada, isto é, sem necessidade de obter autorização ou licença e sem ficar sujeita a censura" (SANTOS, 2011, p. 132). O objetivo desta liberdade de criação seria o de permitir que cada pessoa exerça sua criatividade sem barreiras, sem impedimentos indevidos. O que representa de logo uma contradição com características típicas dos direitos autorais, uma vez que em diversas hipóteses uma pessoa pode precisar de autorizações, de intermediários e de pagamentos para poder se basear em algo já criado e assim exercer sua criatividade.

Este direito de participar do ambiente cultural seria possivelmente uma manifestação dos direitos culturais semelhante ao acesso à cultura. Seria assim um acesso interativo à cultura, não apenas um simples gozo dos produtos culturais oferecidos, o que se adéqua às exigências de interatividade típicas dos padrões da cibercultura. Apesar de não estarem previstos manifestamente nos textos constitucionais e nos de direitos humanos, o direito de acesso à cultura é essencial para a personalidade e para o pleno viver e exercer cidadania.

$\mathrm{O}$ acesso à cultura é objeto de direito fundamental. É verdade que, ao ler a constituição, particularmente 0 art. 5으, não o encontramos expressamente proclamado. Há numerosas referências à promoção ou ao favorecimento da cultura, mas essas são apresentadas como competências ou encargos dos entes públicos. A seguirmos a orientação norte-americana, que distingue as atribuições de competência das atribuições de direitos, poderia por em dúvida que 0 acesso à cultura fosse objeto de um direito fundamental. Mas a orientação entre nós dominante não é assim tão rígida. Não se põe em dúvida que haja um direito fundamental de acesso à cultura (ASCENÇÃO, 2011, p. $10)$.

Haveria então uma relação tensa entre os exclusivos gerados pelo direito de autor e o direito fundamental de acesso à cultura, principalmente levando-se em 
consideração o fato deste acesso ser, no contexto da sociedade da informação com suas características culturais abstratas, um acesso participativo, um direito de colaborar com a cultura que rodeia. Este direito cultural deve ser visto também como um meio. Ou seja, não é apenas o acesso à cultura que está sob tutela, mas sim a cultura como elemento essencial para desenvolvimento pessoal e gozo de diversos outros direitos, também de natureza fundamental, ainda mais com as demandas sociais surgidas com as transformações tecnológicas. Esta combinação de transformações sociais e políticas resultaram na consciência sobre a importância e relevância dos direitos culturais, de um lado, como amálgama sociojurídico dos grupos formadores dos Estados contemporâneos e, de outro, como elemento essencial na construção das identidades e da formação da pessoa, além do papel crucial para o desenvolvimento econômico (SOUZA, 2012, p. 45).

Porém, reconhecer a natureza fundamental do direito de acesso à cultura (envolvendo também sua colaboração com a cultura) não é suficiente para satisfazer expectativas sociais, pois é necessário haver tanto políticas públicas de promoção de cultura, a exemplo dos fomentos culturais, quanto deve haver reanálises de vários aspectos que interagem com a exploração econômica da cultura. Em outros termos, sem políticas públicas culturais e sem uma reinterpretação da relação entre cultura e direitos autorais, tal direito fundamental, necessário para pleno exercício da personalidade e cidadania, não encontrará satisfação.

Os direitos exclusivos criados pela lógica tradicional dos direitos autorais, enfatizando seu aspecto patrimonial e econômico, continuarão limitando o acesso à cultura, tanto no que diz respeito ao acesso propriamente dito, quanto à possibilidade de participar na criação do ambiente cultural. Daí a necessidade de pensar e ressaltar novos modelos de direitos autorais que sejam compatíveis com as características culturais da sociedade da informação, sem que representem ao mesmo tempo barreiras à exploração econômica dos produtos culturais. Já há iniciativas que buscam reequilibrar esta equação no contexto da cibercultura, o que em algum momento influenciará na reforma oficial dos direitos de autor. $O$ que passa a ser examinado a seguir. 


\section{NOVOS MODELOS DE DIREITOS AUTORAIS PARA NOVAS DIMENSÕES DAS LIBERDADES NA CIBERCULTURA}

O fato do sistema tradicional de proteção legal a conteúdo autoral criar limites às liberdades de expressão surge de seu aspecto patrimonial, surge do fato da tutela jurídica dos interesses do autor poder ser usado para controle de reprodução e usos das obras, o que termina permitindo a satisfação de interesses patrimoniais inerentes à exploração econômica dos produtos culturais. O copyright, expressão que representa 0 sistema norte-americano de tutela legal das criações autorais que serve como parâmetro quase mundial de legislação autoral, deu cabimento a distorções em sua própria aplicação, já que tem como proposta uma clausura de possibilidades de uso de conteúdo cultural. Distorções no sentido de extrapolações, mal usos ou usos incoerentes com outras demandas sociais.

Este modelo de direitos autorais surge como forma representativa de pretensões hegemônicas de uma classe dominante, resultando não exatamente de uma conquista de criadores, mas da uniformização dos esforços de livreiros e editores para conter a reprodução descontrolada de obras de arte, e assim preservar seus interesses econômicos (FRAGOSO, 2012, p. 156). Então, apesar do conteúdo pessoal, está na essência do direito de autor, sua natureza econômica. Esta conotação econômica dada aos direitos autorais, com seu esquema de autorizações, usos exclusivos e direitos reservados, interessa a uma determinada classe que, de início detinha os meios necessários para expressar as manifestações criativas.

Os direitos reservados de uso de bens culturais se concentrados indevidamente permitem a criação de uma espécie de oligopólio cultural, pois seriam as empresas de transmissão e distribuição desse conteúdo que ditariam as regras do mercado de culturas, cabendo ao sistema legal não permitir que qualquer pessoa crie algo próximo, ou derivado do que já está sob "proteção".

Este raciocínio se enfraquece quando os donos dos veículos de intermédio (editoras, gravadoras dentre outros) enfrentam os novos meios de divulgação e 
expressão, como a internet, e novos comportamentos sociais típicos da cibercultura, como o dilúvio de informações e o compartilhamento de dados digitais.

A internet surge para a sociedade civil como um instrumento que promete uma quase irrestrita liberdade de acesso à informação e um potencial até então inatingível de participação democrática, seja em discussões políticas, seja em produção artísticocultural. Em perspectiva, o ciberespaço promete realizar ideais da modernidade, pois nele a igualdade se manifesta pela possibilidade de cada pessoa, independente de suas características, expressar informações, a liberdade surge por meio das possibilidades de acesso, navegação e comunicação, e a fraternidade vem como consequência das conexões promovidas em ambiente virtual (LÉVY, 1999, p. 254).

É possível que estas promessas fiquem apenas em planos abstratos e não se materializem, até porque para isso seria necessário que cada cidadão do mundo possuísse meios para acessar a rede, o que não ocorre por causa de inúmeros problemas envolvendo a inclusão digital. Porém, os impactos da cibercultura nas liberdades de expressão e criação, bem como na forma de pensar os direitos autorais são bastante manifestos e significativos. Se antes os donos dos meios necessários para expressas ideias e obras possuíam mecanismos para criar uma espécie de oligopólio da comunicação, hoje com a internet é consideravelmente mais fácil driblar as grandes corporações e poder se expressar.

Com um simples vídeo posto em um blog individual, um criador pode exibir sua produção, seja ela um curta, um clipe ou uma animação. Uma banda pode oferecer gratuitamente em seu website suas composições até então não registradas por uma grande empresa para poderem assim divulgar sua arte.

Mas, não é apenas nos meios de comunicação que a cibercultura provoca impactos, pois a própria forma de comercializar, de disponibilizar e apresentar uma modalidade de expressão artística sofre alteração com este novo parâmetro cultural. $O$ fato de diversas práticas associadas a consumo, acessos, e publicidade ocorrerem hoje em ambiente digital colabora com a problemática dos direitos autorais na internet e para a cibercultura, tendo em vista que a materialização do produto cultural não encontra suporte tangível, e isto choca com ideias tradicionais sobre os direitos de 
autor. Tradicionalmente se entende que uma obra protegida por direitos autorais é aquela "que constitui exteriorização de uma determinada expressão intelectual, inserida no mundo fático em forma ideada e materializada pelo autor" (BITTAR, 2004, p. 23). E que esta obra requer esforço intelectual de seu autor que produz um bem a ser inserido materialmente na realidade fática (BITTAR, 2004, p. 23). Exteriorização e materialização que, na cibercultura, podem ser, como frequentemente o é, realizadas de forma imaterial.

A inexistência de suporte fático para afirmar que a obra deve estar materializada em algo já dificulta a incidência de direitos autorais, ou ao menos sua proteção fica bastante insegura. Outro motivo pelo qual seria possível afirmar a incompatibilidade dos modelos tradicionais de direito autoral após surgimento da internet e de padrões culturais correspondentes seria o de que o modelo tradicional de tutela da produção artístico-cultural exigia um intermediário que facilitasse o contato entre obra e público consumidor daquele produto, e com a internet esta intermediação não é mais necessária, devolvendo ao artista (o criador propriamente dito) o controle sobre sua obra, caso assim o opte.

Diante desta hipotética pouca importância do intermediário para negócios culturais com o surgimento da internet, o modelo de negócio que se baseia no esquema copyright de direitos de autor pode estar sob ameaça de extinção, caso se concretizem transformações culturais potencializadas pela cibercultura. Diversas características desta cibercultura, (participação, coletividade, conectividade, virtualidade e outras) provocam um declínio do modelo de negócio baseado no esquema autor e intermediário (LÉVY, 1999, p. 139).

A internet e a cibercultura demonstram então não apenas um potencial para dinamizar o exercício de liberdades fundamentais, como também potencial para mexer na produção econômica que envolve acesso à cultura. Além disto, transformações econômicas (também alinhadas às transformações nas tecnologias da informação), alteram as formas de realizar negócios culturais, seja porque a participação de forma geral está facilitada por causa da navegação em rede, seja por causa de valores econômicos que se potencializam na sociedade da informação. A criatividade, por 
exemplo, torna-se um grande negócio seja compreendida como algo exercido com fins lucrativos, seja compreendido apenas como algo que se exerce no intuito de participar da produção de cultura, de participar de seu próprio ambiente cultural.

A cultura digital promete um mundo de criatividade incrivelmente diversa que pode ser fácil e amplamente compartilhada. "E à medida que tal criatividade se aplicar à democracia, será possível que uma vasta parcela de cidadãos utilizem-na para expressar, criticar e contribuir com a cultura que os rodeia" (LESSIG, 2005, p. 184). A colaboração propriamente dita, a participação e cooperação representam hoje objetivos do cidadão, não necessariamente interessado em obter ganhos patrimoniais com sua contribuição à cultura que o rodeia. Exemplos como os do Free Software, do Linux, das tecnologias da informação com códigos abertos, demonstram como há pessoas interessadas em formas de criação coletiva e colaborativa, ainda que isto não traga benefícios financeiros. A interatividade promovida pelas tecnologias da informação e exigências sociais da cibercultura reformulam a relação entre a obra e aquele que tem acesso a ela, permitindo que este seja também criador em colaboração e exemplos como o do Wikipédia e do Creative Commons demonstram como há uma demanda social para tal (SANTOS, 2011, p. 147).

Porém, todas essas promessas de liberdade, criatividade e colaboração vindas da cibercultura enfrentam uma imensa barreira legal, qual seja, a manutenção das regras tradicionais de proteção aos direitos autorais. Para que toda essa abertura democrática ao acesso à informação e liberdade de criação ocorra, é necessário repensar o tratamento jurídico dado ao conteúdo autoral produzido, pois novos modelos de negócio surgem e exigem seu reconhecimento jurídico. Diante dos impactos produzidos pelo desenvolvimento tecnológico nos institutos jurídicos duas hipóteses surgem, uma a de que as normas jurídicas não sofrerão mudanças, outra a de que o sistema jurídico adotará medidas adaptativas, criando novas respostas jurídicas a mudanças de comportamentos sociais, a exemplo da possível subversão ao modelo tradicional de propriedade intelectual (LEMOS, 2005, p. 66).

Quando se fala em subversão ao modelo tradicional de regulamentação de direitos autorais, isto não necessariamente precisa representar eliminação de proteção 
legal às produções criativas $O$ que está em discussão não é a necessidade de uma proteção legal, pois isso é indiscutível, mas sim o modelo de proteção oferecido pelos mecanismos legais tradicionais que podem, ao invés de incentivar a expressão criativa, reprimir iniciativas de produção de cultura, em decorrência do sistema em que a prévia autorização para usos é regra geral.

Caso sejam mantidas estas regras, cuja lógica é a de fechamento e de uso proprietário, que foram criadas num contexto anterior ao da difusão global da internet e aos parâmetros culturais da cibercultura, a manifestação criativa pode ser inibida em prol de interesses econômicos vindos de grandes corporações titulares da propriedade intelectual que sirva como matéria prima para exploração e crescimento do ambiente cultural. Corporações estas que podem se interessar em preservar o modelo legal de intermediação, pois quaisquer outras formas de acesso à cultura e participação no ambiente cultural poderão ser taxadas de ilegais, sem reconhecimento jurídico, clandestinas e sem segurança jurídica.

Uma vez que a hipótese seja a de excesso de regulação de direitos autorais patrimoniais, com previsão de punições excessivas para insignificantes violações, e se este excesso fizer com que empreendimentos criativos de inovação passem ser fiscalizados ao ponto de serem exigidos gastos volumosos com pagamentos de licenças, haverá bem menos inovações e criatividade do que se houvesse uma alternativa à ilegalidade (LESSIG, 2005, p. 192). Ou seja, em tempos de economia criativa, modelo econômico que prioriza incentivos ao empreendedorismo e valoração da informação, a tutela jurídica tradicional da propriedade intelectual serviria como uma barreira, impedindo parcela considerável da sociedade civil de cooperar, criar e participar com a construção de seu ambiente cultural.

Com esta hipótese, tal parcela da sociedade querendo maior grau de interação com seu ambiente cultural procurará meios que ficam à margem da legalidade, e a resposta para retirar essa ilegalidade passa por escolhas entre obedecer estritamente a legislação da forma como ela está, ou modificar a norma jurídica, e quando os malefícios da manutenção de tradições se sobrepõem a seus próprios benefícios, é caso de considerar a possibilidade de mudanças (LESSIG, 2005, p. 201). 
Novos parâmetros para uma cultura de direitos autorais compatível com a cibercultura já existem, a exemplo do sucesso dos softwares de código aberto, dos recursos educacionais abertos e pelas licenças Creative Commons. As licenças oferecidas por esta organização procuram atender os diversos interesses e demandas das diversas classes envolvidas com a produção cultural, desde artistas e criadores, a produtores em geral, permitindo que o autor interessado receba a oportunidade de escolher dentre opções de licenças disponíveis (LEMOS, 2005, p. 85). Ao dar alternativas sobre o grau de controle sobre os usos das obras, o Creative Commons cria um modelo que satisfaz exigências da cibercultura que envolvem liberdades, escolhas e democratização das atividades criativas, representando, sob determinada ótica, uma mudança cuja iniciativa não parte do poder estatal, mas sim da sociedade civil (LEMOS, 2005, p.83).

Estas alternativas criadas à proteção excessiva dos produtos culturais pelos direitos autorais em momento algum representam abstenção de ganhos econômicos com a exploração comercial das obras. Representam o surgimento de novos modelos econômicos que satisfazem tanto a necessidade de proteção e exploração da propriedade intelectual, quanto a necessidade de acesso à cultura e fruição de direitos culturais, inseridos numa cultura geral de livres manifestações.

Havendo alternativas, ainda que criadas extraoficialmente por instituições e vontades privadas, é necessário repensar os modelos normativos de direitos sobre a propriedade intelectual, pois tais representam ventos de mudanças e clamores sociais que caracterizam um padrão cultural vigente na sociedade da informação. Sem esta reanálise o sistema padrão de direito autoral poderá recair em obsolescência, retratando um modelo anacrônico tanto de exercício de liberdades quanto de negócio econômico.

\section{CONSIDERAÇÕES FINAIS}

O objetivo deste trabalho foi o de analisar se as liberdades de expressão ganham nova dimensão com o surgimento dos padrões de comportamento surgidos 
com a cibercultura, satisfazendo com maior grau os direitos fundamentais que estão relacionados com acesso à cultura, bem como analisar se o sistema de regulamentação dos direitos autorais está compatível com este hipotético novo contexto, ajudando ou impedindo a plena fruição destas liberdades culturais.

No que diz respeito às liberdades de expressão, considerando o argumento de que este nome não é suficiente para resumir todo um complexo de liberdades relacionadas com formas de manifestação, pois ela engloba comunicação, acesso à informação e cultura, e liberdades de criação e participação cultural, constatou-se que as ferramentas tecnológicas oferecidas pelas transformações na tecnologia da informação ocorridas no século XXI potencializam o exercício das liberdades fundamentais, então ganham sim uma nova proporção.

O ambiente digital criado pela rede mundial de computadores cria, ao menos em abstrato, um ambiente livre de barreiras físicas para expressar manifestações culturais e, consequentemente, gozar delas. Desta forma, a vontade de exercer liberdades encontra na internet um meio em que intermediários entre produção cultural e público tornam-se desnecessário, pois tudo ficaria em rede, disponível para acesso. E ainda, o fluxo de informações disposto na rede mundial de computadores colabora, também em potencial, com a atividade criativa, com a criação de produtos culturais, considerando as amplas possibilidades de trocas culturais e de acessos. Em outros termos, a internet potencializa não somente a liberdade de expressar cultura, mas também a liberdade de acessar a produção cultural. O que confirma a existência de outras dimensões às liberdades artísticas surgidas no contexto da sociedade da informação.

Em ponto seguinte, o trabalho se propôs a analisar se o sistema de regulação dos direitos autorais colabora com a fruição de direitos culturais, ou representariam barreiras para pleno exercício destes direitos fundamentais. É certo que os direitos de autor são necessários para proteção das manifestações do esforço criativo, são necessários sob diversos aspectos, seja o da segurança, o da autoria moral ou o da exploração comercial da economia da cultura. Mas, surgem problemas quando esta regulação se confronta com aspectos da ideologia que integra a cibercultura, o que pode transformar as normas jurídicas numa forma de conter o exercício das liberdades 
culturais, em decorrência das exigências de autorização e dos direitos exclusivos criados pelos direitos de autor.

Diante deste cenário, torna-se possível o argumento de que o vigente sistema de proteção legal às manifestações criativas é incompatível com necessidades e exigências sociais surgidas no parâmetro da cibercultura. $O$ que, em tese, pode fazer com que outros caminhos sejam trilhados para exercer as liberdades de acesso e de fruição da cultura. O problema de trilhar outros caminhos está na possível ilegalidade desta subversão ao modelo tradicional de direitos autorais.

No último ponto do trabalho foi então analisada a forma como novos modelos de proteção à autoria podem tornar mais adequada a relação entre direito autoral e liberdades culturais no contexto da sociedade da informação. No intuito de demonstrar que é possível existir proteção sem que isto represente barreiras à circulação de bens culturais, e é possível haver alternativas ao modelo legal vigente sem que se recaia em ilegalidade, foram vistos instrumentos e iniciativas que protegem as obras criadas mas permitem livre acesso e livre participação cultural.

Existem alternativas que podem deixar o sistema de direitos de autor mais compatível com os anseios de participação no ambiente cultural, seja pela liberdade de acesso, seja pela liberdade de criação. Tais alternativas podem estar em iniciativas estatais, como possíveis reformas da legislação autoral, ou em iniciativas não-estatais, surgidas da sociedade civil (a exemplo do free software, Linux, Creative Commons dentre outras). Tais alternativas não representam de forma alguma uma abstenção de proteção, tampouco uma abertura cultural que inviabiliza ganhos financeiros aos criadores. Representam o diagnóstico de que novos modelos de negócio com base em novos parâmetros de direitos autorais são possíveis, tornando a produção cultural lucrativa sem prejudicar a fruição de direitos fundamentais de liberdade e de cultura. Enfim, há meios de garantir as liberdades de expressão em tempos de internet, sem que isto represente descontrole absoluto do espaço virtual, sem que isto represente ausência de direitos autorais, mas sim com alternativas legais e boa dose de boa vontade política e econômica. 


\section{REFERÊNCIAS}

ASCENSÃO, José de Oliveira. Direito Autoral. Rio de Janeiro: Renovar, 1997.

. Direito fundamental de acesso à cultura e direito intelectual. In: SANTOS, Manoel Pereira dos (Coordenador). Direito de Autor e direitos fundamentais. São Paulo: Ed. Saraiva, 2011. Páginas 09 a 44.

BITTAR, Carlos Alberto. Direito de Autor. Rio de Janeiro: Forense, 2004.

BOBBIO, Norberto. Dicionário de política. Brasília: editora universidade de Brasília, 1986.

FARIAS, Edilsom Pereira de. Estatuto teórico da liberdade de expressão e comunicação. In: LOIS, Cecília Caballeros e BASTOS JUNIOR, Luiz Magno Pinto (coordenanores). A constituição como espelho da realidade: interpretação e jurisdição constitucionais em debate: homenagem a Silvio Dobrowolski. São Paulo: LTr, 2007. Páginas 156 a 180.

FRAGOSO, João Henrique da Rocha. Direito de Autor e Copyright: Fundamentos Históricos e Sociológicos. São Paulo: QuartierLatin, 2012.

KRETSCHMANN, Angela. O papel da dignidade humana em meio aos desafios do acesso aberto e do acesso universal perante o direito autoral. In: SANTOS, Manoel Pereira dos (Coordenador). Direito de Autor e direitos fundamentais. São Paulo: Ed. Saraiva, 2011. Páginas 76 a 103.

LEMOS, Ronaldo. Direito, Tecnologia e cultura. Rio de Janeiro: FGV, 2005.

LESSIG, Lawrence. Cultura Livre: como a grande mídia usa a tecnologia e a lei para bloquear a cultura e controlar a criatividade. São Paulo: Trama, 2005.

LÉVY, Pierre. Cibercultura. São Paulo: Ed. 34, 1999.

RIVERO, Jean. Liberdades públicas. São Paulo: Martins Fontes, 2006.

SANTOS, Manoel Pereira dos. Direito de autor e liberdade de expressão. In: SANTOS, Manoel Pereira dos (Coordenador). Direito de Autor e direitos fundamentais. São Paulo: Ed. Saraiva, 2011. Páginas 129 a 158.

SOUZA, Allan Rocha de. Direitos Culturais no Brasil. Rio de Janeiro: Ed. Beco do Azougue, 2012. 